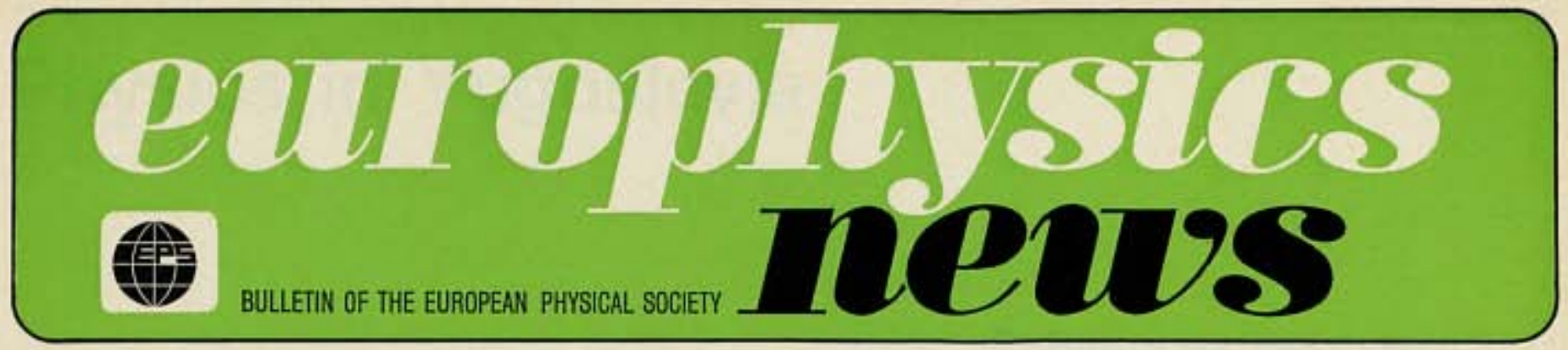

\title{
The Fate of ESRIN
}

At its meeting on December 8-9, the Council of ESRO - the European Space Research Organization - approved the text of a comprehensive resolution on the reform of the Organization. Although the meeting was marked by what the press communiqué called a " highly constructive atmosphere of collaboration" and the Council recognized with gratitude the valuable scientific contribution so far made by ESRIN, the Organization's Institute for Basic Scientific Research at Frascati, Italy, it nevertheless regretfully concluded that circumstances force the termination of ESRIN's activities by September 1973.

The problems facing ESRO, of both a political and budgetary nature, have been serious and, it is a source of relief that, in effect, minimum expenditures over the next 8 years have been agreed averaging approximately $100 \mathrm{M} \$ /$ year. The immediate future of ESRO, which at one time seemed threatened, is therefore assured. It is appreciated also that this agreement has only been possible following lengthy negotiations and the Council has been forced to make economies whilst reassessing its whole programme.

Nevertheless the proposal to discontinue the activities of ESRIN has caused great concern within the Plasma Physics Division of the European Physical Society and has prompted the Chairman of the Division, Bo Lehnert, to issue the following communication summarizing the views expressed.

\section{Essential Functions of ESRIN}

Since the ESRIN laboratory came into being, the members of the Board of the Plasma Physics Division of the European Physical Society have established numerous personal and scientific contacts with the ESRIN staff. They have thus had the opportunity of obtaining a clear view of the high value and quality of the scientific work being performed within this group at Frascati. Although the ESRIN laboratory was only established quite recently, it possesses a well qualified staff of scientists and is well equipped with modern experimental facilities. Apart from the significant contributions which ESRIN makes to the field of cosmical plasma physics (see e.g. the Annual ESRO Reports), its activities also form an important link with other branches of physics. The theoretical and experimental work carried out at ESRIN also represents an important and inherently needed stage in the preparation of relevant space experiments, and is the proper means for the reduction and understanding of data obtained from the space programme conducted by ESRO.

In view of these facts, the ESRIN laboratory must be considered an essential part of the activities within ESRO, and, by no means, a luxury. We thus feel that the proposal of the ESRO Council to relinquish ESRIN is most unfortunate and would lead to a significant step backwards in the development of European space research severely decreasing the stand- ard of work and the possibilities for international cooperation. For this reason any apparent saving in the budget would be more than offset by the decrease in efficiency of ESRO and by increased pressure on national research budgets.

\section{Future of the Laboratory}

It is understood that "...the DirectorGeneral of ESRO will continue to explore possible scientific uses which the Italian authorities may be able to make of that part of ESRIN which will not be occupied by the ESRO technology dissemination service..." but it is felt that insufficient weight has been given to the importance of ESRIN's scientific contributions to Európean space developments which are set out below.

\section{The Role of ESRIN}

1. The observational data to be obtained from the space programme are in most cases highly complicated. They must be analysed in detail and thoroughly understood to have any scientific and practical value. This evaluation can only be done by qualified scientists who have the opportunity to check both theoretically and experimentally observational data and proposed theories through modern and wellequipped laboratory experiments.

2. ESRIN is so far the only large international laboratory in W. Europe with facilities available for what can be termed laboratory space physics. If ESRIN is closed, the 
workers within the entire space programme of ESRO, as well as those within similar activities at various other institutes and organizations throughout Europe, will necessarily be forced to obtain their knowledge of laboratory experiments on space research from places outside Europe. In order to obtain this essential knowledge, ESRO would be dependent on "foreign" sources.

3. ESRIN is also unique in the sense that it forms an international centre for space physics in Europe, at which there is fruitful collaboration between scientists of various countries. The development of science in Europe requires that certain projects are tackled on a European scale, rather than - with unavoidable duplication - in various national centres. It will be interpreted as a sign of disintegration of European collaboration if an institute such as ESRIN is closed. Moreover it will inevitably lead to increasing pressure on the national research budgets. In this connexion it should be noted that a number of inter-

\section{Cryogenics}

international journal of low-temperature engineering and research.

Cryogenics is internationally recognised as the leading journal in the field of low-temperature engineering and research. Each issue contains review articles and original papers on subjects as varied as phase equilibria, slush hydrogen and superconducting train suspensions. Complementary to the contributed papers are the research and technical notes describing preliminary results and experimental features, and letters to the editor on recent areas of discussion and controversy. One-year subscription (six issues) $£ 15.00$ (\$37.50) from IPC Science and Technology Press, 32 High Street, Guildford, Surrey, England. national research centres have been established with great success in other fields of research. Examples to be mentioned here are the IAEA Institute of Theoretical Physics in Trieste, and CERN in Geneva.

4. The ESRIN Institute has been completed only quite recently and has just begun to work at its full capacity. The cost of ESRIN represents a few $\%$ of the total budget of ESRO, and less than $10 \%$ of the part spent on scientific research. These are modest figures in view of the importance of the fundamental scientific problems involved, and of their technological and industrial applications.

5. If an international research centre is to function properly the scientific community must have confidence in the stability of the policies of the governing bodies. It would set a bad precedent affecting not only ESRO if support for ESRIN is now to be discontinued.

6. If ESRIN were to be closed down, a well-working team would be dissolved. Since it appears doubtful that it can be absorbed in existing national European centres working in this field of research, its special skill and experience would, to a large extent, be lost to European countries.

7. It should finally be observed that the loss of ESRIN would be felt particularly by the smaller countries which would encounter great difficulties in readjusting their work in space research to a situation arising from such a loss.

Almost two years are due to elapse before the scheduled closure. This should allow time for some reconciliation to be made between the scientific needs and budget exigencies.

\section{Letter to the Editor}

\section{Sir,}

With satisfaction and understanding I have read Prof. Jansen's article "More Physicists than Jobs in the USA : A Lesson for Europe" in the recent issue of Europhysics News*.

It seems to me that the crisis our American colleagues are now trying to overcome has deeper and more general roots and therefore we may expect that European physics will sooner or later meet with similar difficulties.

Prof. Jansen remarks quite correctly, that if the same were to happen in Europe, the situation would be much more critical because of the somewhat lower vitality and mobility of European physicists. I think that national, linguistic as well as political barriers still existing in Europe may cause the feared crisis to become incomparably more profound and difficult than the present situation in the USA.

Article 2 of the Constitution of the EPS states that "The purpose of the Society is and shall be to contribute to and promote the advancement of physics in Europe...". I consider it therefore to be the first duty of our Society to analyse well in advance the possible trends and measures to be taken in order to prevent or, at least, to lighten the heavy consequences such a crisis, if it were to happen, may bring to our community.

May I suggest therefore that this problem be brought up for discussion at the next meeting of the Executive Committee? May I further suggest that the Physics and Society Committee be entrusted with a far reaching and thorough investigation of the present situation and its trends?

\section{F. Janouch, Prague}

